\title{
Nonlinear Finite Element Model Calibration of a Reinforced Concrete Column with Distributed Plasticity
}

\author{
Hélder Maranhão ${ }^{1}$ Humberto Varum² Mário Pimentel $^{3}$ \\ ${ }^{1}$ CONSTRUCT-LESE, Department of Civil Engineering, Faculty of Engineering, University of \\ Porto, Rua Dr. Roberto Frias, 4200-465 Porto, Portugal (helder.maranhao@fe.up.pt) ORCID \\ 0000-0001-5411-5936; '2CONSTRUCT-LESE, Department of Civil Engineering, Faculty of \\ Engineering, University of Porto, Rua Dr. Roberto Frias, 4200-465 Porto, Portugal \\ (hvarum@fe.up.pt) ORCID 0000-0003-0215-8701; ${ }^{3}$ CONSTRUCT-LABEST, Department of Civil \\ Engineering, Faculty of Engineering, University of Porto, Rua Dr. Roberto Frias, 4200-465 \\ Porto, Portugal (mjsp@fe.up.pt) ORCID 0000-0001-8626-6018
}

\begin{abstract}
Nonlinear finite element models, whenever is possible, shall be validated using experimental data. The efficiency of the nonlinear analysis depends on the choice of finite element models parameters. In the present work the calibration is conducted with the goal of observe and minimize the difference between the experimental data and the nonlinear finite element models, using two distributed plasticity modelling approaches. Several models with different parameters of distributed plasticity are used herein and compared against experimental data. The results show that the nonlinear analysis, when associated to a proper modeling strategy, is capable to successfully simulate experimental data.
\end{abstract}

Author Keywords. Model Calibration, Experimental Data, Cyclic Envelope Curve, Pushover Analysis, Fiber Model.

Type: Research Article

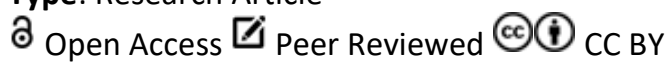

\section{Introduction}

The nonlinear finite element models often have a large amount of uncertainty and therefore they shall be calibrated recurring to experimental data. This procedure is termed as nonlinear finite element model calibration and has special interest in the field of structural dynamics and seismic engineering research. Due to the amount of uncertainties, nonlinear modeling is not currently used for structural design, rather to assess the structural behavior of existing structures.

The object of the present study aims to calibrate force-based nonlinear finite element models of a reinforced concrete column with distributed plasticity against experimental data. A key point in the performance of force-based approach is the adoption of structural models more refined than those usually adopted in linear analyses, including a correct representation of the nonlinear phenomena. In this work two modelling approaches with different plastic distributions are adopted, and their numerical results are compared with the experimental outcome obtained from Tanaka's experimental work (Tanaka 1990).

The distributed plasticity models discretize the continuum along the member length and through the cross sections into small finite elements with nonlinear hysteretic constitutive properties that have numerous input parameters. This fundamental level of modeling offers the most versatility, but it also presents the most challenge in terms of model parameter calibration. Distributed plasticity models average the nonlinearity over a finite element by considering the possibility to form plastic hinges at different evaluation points of the element 
and calculating weighted integrals of the section responses. Fiber models subdivide a section with many finite elements (Figure $1(a)$ ) and nonlinearity is related to the stress-strain relationship of a single finite element (Deierlein, Reinhorn, and Willford 2010).

The material nonlinearity is defined at any element section and the element behavior is derived by a weighted integration of the section. Since the element integrals are assessed numerically, only the behavior of selected sections at the integration sections is checked.

The constitutive behavior of the cross-section is formulated according classical plasticity theory, in terms of stress and strain resultants and derives of the discretization of the crosssection layers into fibers. In a fiber model, members are discretized into segments represented by discrete layers, and at the sectional layers level, into finite regions.

In the present work it has been used two types of distributed plasticity, denominated as finite length hinge model (Figure 1(b)) and distributed fiber formulation model (Figure 1(c)).

The finite length hinge model is a distributed plasticity formulation with designated hinge zones at the member ends. Cross sections in the inelastic hinge zones are characterized through fiber section integrations that impose the assumption that plane sections remain plane. The inelastic hinge zone is defined with a fixed length while the remaining element out the hinge zone remains elastic (Deierlein, Reinhorn, and Willford 2010).

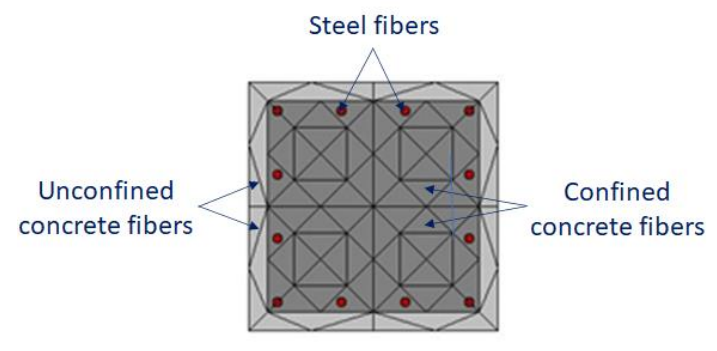

(a)

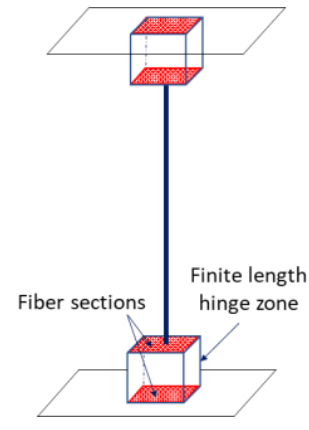

(b)

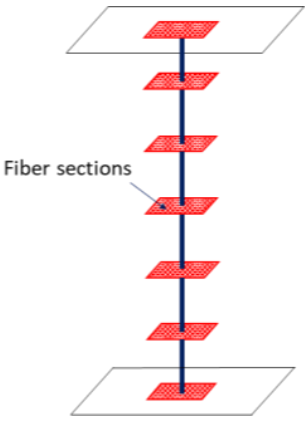

(c)

Figure 1: (a) Integration section (b) Finite length hinge model (c) Distributed fiber formulation model

The distributed fiber formulationmodels distribute plasticity along the element length by numerical integrations through the member cross sections. In this formulation it is imposed that sections remain plane, where uniaxial material fibers are numerically integrated over the fiber section layers in order to obtain stress resultants, the moment-curvature and axial forcestrain relations. The fiber sections layers parameters are then integrated numerically along the member length, using displacement or force interpolation functions (Deierlein, Reinhorn, and Willford 2010).

\section{Calibration Methodology}

The calibration methodology consists to perform a comparison between the cyclic envelope curve obtained from experimental data and the column capacity curves response parameters to find which type of nonlinear finite element model describes better the experimental results. The capacity curves were obtained by nonlinear numerical simulation known as the static pushover analysis.

The static pushover analysis was applied to both finite length hinge and distributed fiber formulation models.

For a better understanding, the following flowchart (Figure 2) gives an overview of the calibration process applied to the present analysis. 


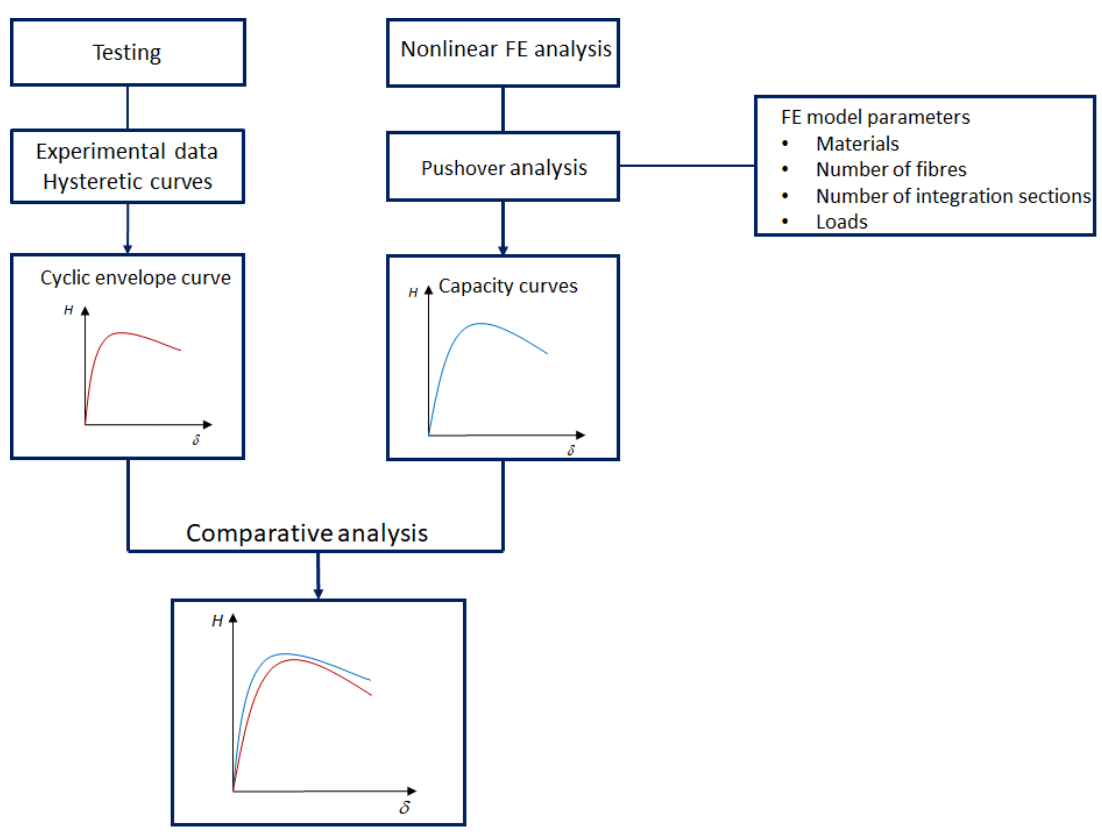

Figure 2: Overview of the nonlinear model calibration process

\section{Testing and Experimental Data Acquisition}

\subsection{Test unit description}

From Tanaka's experimental work a set of reinforced concrete columns units were built up and tested (units 5 to 8), incorporating a true cantilever column setup (Tanaka 1990). Only the test unit 5 is of interest for the present analysis. The referred unit have a total height of 2750 $\mathrm{mm}$ composed by a $1650 \mathrm{~mm}$ height column and $1100 \mathrm{~mm}$ thick base block (Figure 3(a)). The column has a $550 \times 550 \mathrm{~mm}^{2}$ cross-section (Figure $3(b)$ ). The base block is composed by a concrete with higher strength than that of column portion in order to prevent failure occurring in the block itself.

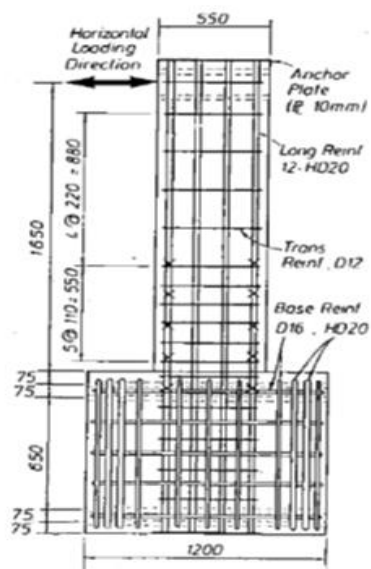

(a)

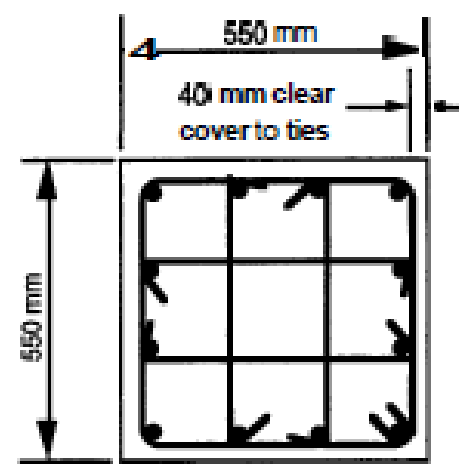

(b)

Figure 3: (a) Test unit 5 longitudinal section (Tanaka 1990)

(b) Test unit 5 cross section (Tanaka 1990)

The mechanical properties, materials and the level of axial force of the tested unit are listed in Table 1 and Table 2. 


\begin{tabular}{cccccc}
\hline $\begin{array}{l}\text { Unit } \\
\text { N. }^{\circ}\end{array}$ & $\begin{array}{c}\text { No. of } \\
\text { Hoop Sets }\end{array}$ & $\begin{array}{c}\text { Transverse } \\
\text { bar } \\
\text { diameter } \\
(\mathrm{mm})\end{array}$ & $\begin{array}{c}\text { Spacing } \\
\text { centers }\end{array}$ & $\begin{array}{c}\text { Longitudinal } \\
\text { bar } \\
\text { diameter } \\
(\mathrm{mm})\end{array}$ & $\begin{array}{c}\text { Clear } \\
\text { cover } \\
\text { c }\end{array}$ \\
\hline 5 & 6 & 12 & 110 & 20 & 40 \\
\hline
\end{tabular}

Table 1: Rebar diameter and concrete clear cover (Tanaka 1990)

\begin{tabular}{|c|c|c|c|c|c|c|}
\hline \multirow{2}{*}{$\begin{array}{r}\text { Unit } \\
\mathrm{N} .^{\circ}\end{array}$} & \multirow{2}{*}{$\begin{array}{c}\text { Concrete } \\
\text { strength } \\
f_{c} \\
(\mathrm{MPa})\end{array}$} & \multirow{2}{*}{$\begin{array}{c}\text { Axial } \\
\text { Load } \\
P \\
(\mathrm{kN})\end{array}$} & \multicolumn{2}{|c|}{$\begin{array}{c}\text { Longitudinal } \\
\text { Reinforcement }\end{array}$} & \multicolumn{2}{|c|}{$\begin{array}{c}\text { Transverse } \\
\text { Reinforcement }\end{array}$} \\
\hline & & & $\begin{array}{c}\rho \\
(\%)\end{array}$ & $\begin{array}{c}f_{y} \\
(\mathrm{MPa})\end{array}$ & $\begin{array}{c}\rho \\
(\%)\end{array}$ & $\begin{array}{c}f_{y} \\
(\mathrm{MPa})\end{array}$ \\
\hline 5 & 32,0 & 968 & 1,25 & 511 & 1,70 & 325 \\
\hline
\end{tabular}

Table 2: Materials properties (Tanaka 1990)

\subsection{Loading test procedure}

Constant axial compressive load $P$ at a predetermined level, as described in Table 2, was applied to each column unit by a $10 \mathrm{MN}$ servo-controlled hydraulic jack in the testing machine. The cyclic lateral loading $H$ was applied by $500 \mathrm{kN}$ or $1000 \mathrm{kN}$ double acting hydraulic jacks (Tanaka 1990).

\subsection{Treatment of experimental data}

For the calibration, it is needed to build up the cyclic envelope curve, using the hysteretic curve gathered from testing.

A force-deformation curve that envelopes the hysteretic behavior of a component is termed the cyclic envelope curve or more commonly known as the "backbone curve". Cyclic envelopes depend on the loading protocol used in component testing. Deformation capacities, peak strength, and residual strength parameters typically degrade under repeated cyclic loading. In order to build up the cyclic envelope, experimental data key points have been identified and connected at the peak response point, as shown in Figure 4. The hysteretic curve TANAKA9OU 5 corresponds to the tested unit 5.

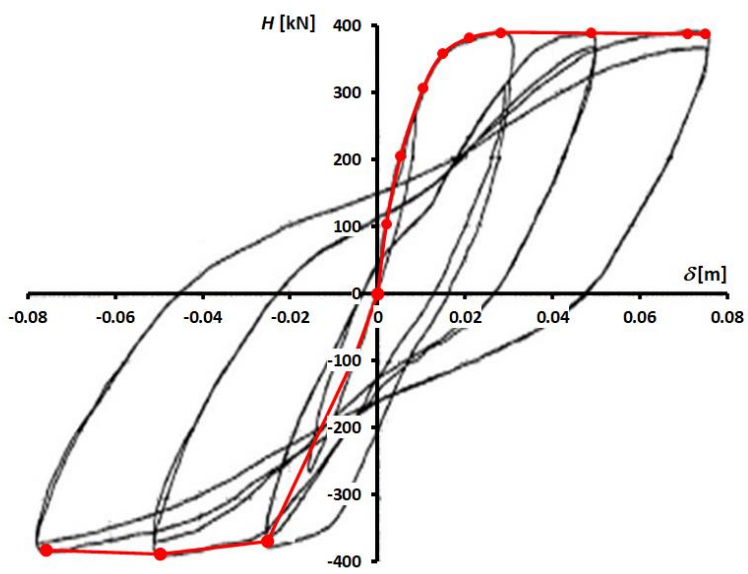

Figure 4: Cyclic envelope lateral force-displacement hysteretic curve TANAKA90U5 (Tanaka 1990)

\section{Nonlinear Finite Element Modeling}

The analysis was performed using SeismoStruct version 2020 (Seismosoft 2020), which is a commercial structural analysis software for dynamic and nonlinear analysis of structures. Three-dimensional finite element models were carried out to run the static pushover analysis. 
The column was modeled as single-degree-of-freedom structural (SDOF) system, at its central axis, considering clamped at the bottom and the tip translation is restrained in the y-direction.

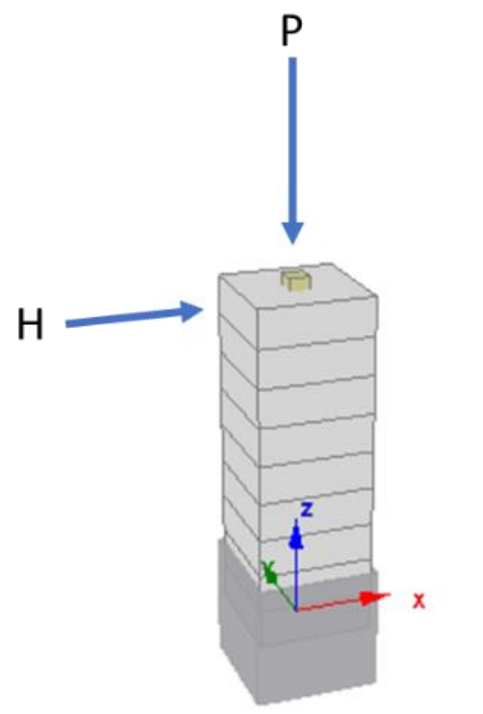

Figure 5: Finite element 3-D model - (Seismosoft 2020)

\subsection{Nonlinear finite element models definition}

The finite length hinge models are defined by performing a combination of hinge relative length with the number of fibers comprising the integration sections. The relative length hinge is defined as $L_{p} / L$, where $L_{p}$ is the hinge length and $L$ is the column total length. Table 3 shows the combinations between the hinge relative length and the number of fibers to perform the hinge finite length model pushover analysis.

\begin{tabular}{ccccc}
\hline FE model & $\begin{array}{c}\text { Test unit } \\
\mathbf{n .}^{\circ}\end{array}$ & $\begin{array}{c}\mathbf{P} \\
\mathbf{( k N )}\end{array}$ & $\begin{array}{c}\text { Number } \\
\text { of } \\
\text { fibers }\end{array}$ & $\begin{array}{c}\mathbf{L}_{\mathbf{p}} / \mathbf{L} \\
\mathbf{( \% )}\end{array}$ \\
\hline FLH-50-10 & 5 & 968 & 50 & 10 \\
FLH-50-15 & 5 & 968 & 50 & 15 \\
FLH-50-20 & 5 & 968 & 50 & 20 \\
\hline FLH-100-10 & 5 & 968 & 100 & 10 \\
FLH-100-15 & 5 & 968 & 100 & 15 \\
FLH-100-20 & 5 & 968 & 100 & 20 \\
\hline
\end{tabular}

Table 3: Combination between hinge relative length and number of fibers comprising integration sections for TANAKA90U5

In the finite length hinge model, only two integration sections are considered, defined at the hinge ends. In line with Figure 6(a) the integration sections are located according Table 4.

\begin{tabular}{cccc}
\hline$z$ & & \multicolumn{1}{c}{$\begin{array}{c}\mathbf{L}_{\mathrm{p}} / \mathbf{L} \\
(\mathbf{\%})\end{array}$} \\
\cline { 2 - 4 }$(\mathrm{m})$ & $\mathbf{1 0}$ & $\mathbf{1 5}$ & $\mathbf{2 0}$ \\
\hline $\mathrm{z}_{1}$ & 0,000 & 0,000 & 0,000 \\
$\mathrm{z}_{2}$ & 0,165 & 0,248 & 0,330 \\
\hline
\end{tabular}

Table 4: Hinge relative length - Finite length hinge model

The model analysis through the distributed fiber formulation approach, is performed combining the number of integration sections and the number of fibers that makes up each integration section, as shown in Table 5. 


\begin{tabular}{lcccc}
\hline FE model & $\begin{array}{c}\text { Test unit } \\
\mathbf{n} .^{{ }^{\circ}}\end{array}$ & $\begin{array}{c}\mathbf{P} \\
\mathbf{( k N )}\end{array}$ & $\begin{array}{c}\text { Number } \\
\text { of } \\
\text { integration sections }\end{array}$ & $\begin{array}{c}\text { Number } \\
\text { of } \\
\text { fibers }\end{array}$ \\
\hline DFF-3-50 & 5 & 968 & 3 & 50 \\
DFF-3-100 & 5 & 968 & 3 & 100 \\
DFF-3-150 & 5 & 968 & 3 & 150 \\
\hline DFF-5-50 & 5 & 968 & 5 & 50 \\
DFF-5-100 & 5 & 968 & 5 & 100 \\
DFF-5-150 & 5 & 968 & 5 & 150 \\
\hline
\end{tabular}

Table 5: Combination between number of integration sections and the number of fibers comprising integration sections for TANAKA90U5

In the distributed fiber formulation, the integration sections are located along the columns according Table 6 in line with Figure 6(b) measured from its barycenter.

\begin{tabular}{ccc}
\hline \multirow{2}{*}{$\mathbf{z}$} & \multicolumn{2}{c}{$\begin{array}{c}\text { Number of integration } \\
\text { sections }\end{array}$} \\
\cline { 2 - 3 }$(\mathbf{m})$ & $\mathbf{3}$ & $\mathbf{5}$ \\
\hline $\mathrm{z}_{1}$ & $-0,825$ & $-0,825$ \\
$\mathrm{z}_{2}$ & 0,000 & $-0,540$ \\
$\mathrm{z}_{3}$ & 0,825 & 0,000 \\
$\mathrm{z}_{4}$ & - & 0,540 \\
$\mathrm{z}_{5}$ & - & 0,825 \\
\hline
\end{tabular}

Table 6: Location of the integration sections - Distributed fiber formulation model

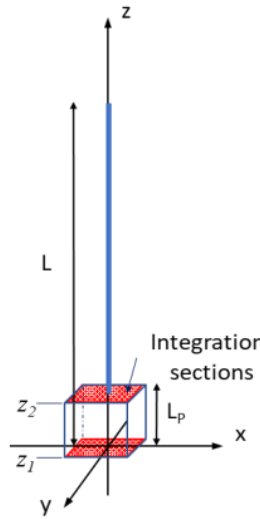

(a)

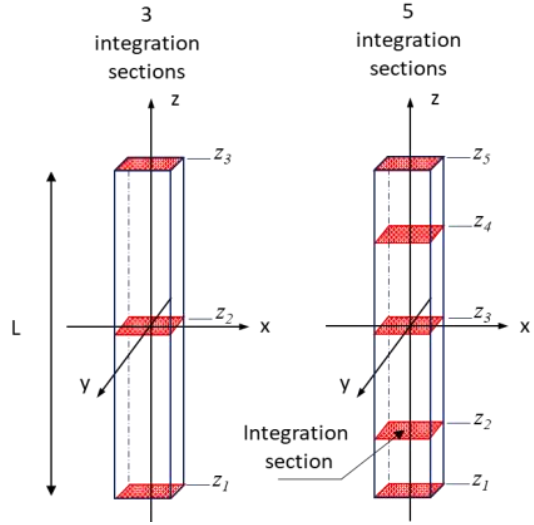

(b)

Figure 6: Integration sections location: (a) Finite length hinge (b) Distributed fiber formulation

The fiber approach is used in SeismoStruct to represent cross-section behavior.

The distributed inelasticity in elements using the force-based approach was implemented according (Neuenhofer and Filippou 1997) formulation. In a force-based element, equilibrium is strictly satisfied and no restraints are placed on the development of inelastic deformations throughout the member. For accuracy reasons, it was implemented the Gauss-Lobatto quadrature, since the analyzed numerical models are defined as force-based.

FIB bulletin 45 (FIB-FIP-CEB 2008) points two integration schemes shall be used for line elements, the Gauss integration method, which is meant for displacement-based models, and Gauss-Lobatto for force-based models. The Gauss-Lobatto integration method, applied to a natural $[-1,1]$ domain, is given by Equation 1.

$$
I=\int_{-1}^{1} f(\xi) d \xi=w_{1}\left(\xi_{1}=-1\right)+\sum_{h=2}^{m-1} w_{h} f\left(\xi_{h}\right)+w_{m} f\left(\xi_{m}=1\right)
$$


The Gauss-Lobatto scheme, $h$ denotes the monitored section and $w$ is the corresponding weight factor. Gauss-Lobatto scheme is favored in force-based elements where monitoring the end sections is important. The Gauss-Lobatto scheme with $m$ integration sections integrates exactly polynomials of degree up to $2 m-3$ (FIB-FIP-CEB 2008).

The following figures shows fiber sections meshing, in which the integration sections have been subdivided whereby the reinforced concrete cross-section discretization is defined.

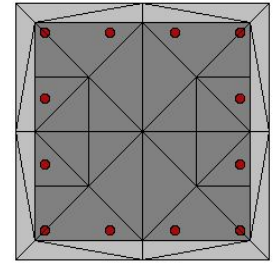

(a)

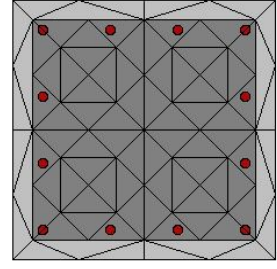

(b)

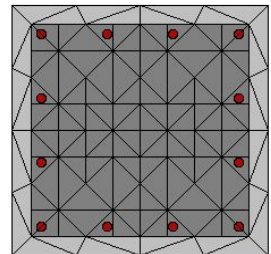

(c)

Figure 7: Meshing: (a) 50 fibers (b) 100 fibers (c) 150 fibers

\subsection{Load implementation}

The incremental loads represent pseudo-static loads that are incrementally increased.

The magnitude of a load at any step is given by the product of its nominal value, and the current load factor, which is updated along the analysis. In pushover analysis, the applied loading usually consists of permanent vertical loads and incremental lateral loads $H_{i}$ in one direction. The magnitude of load increment at any given analysis step $i$ is given by the product of its nominal value $H_{0}$, and the load factor $\theta_{1}$ (Equation 2).

$$
H_{i}=\theta_{i} \cdot H_{0}
$$

\subsection{Nonlinear solution procedure}

The solution algorithm employs the modified Newton-Raphson method. The iterative procedure follows the conventional schemes applied in nonlinear analysis, whereby the internal forces correspond to a displacement increment are computed and convergence is checked. Regarding the convergence criteria, SeismoStruct uses two distinct convergence check schemes criteria, the displacement-rotation and force-moment based. The solution convergence is checked at the end of every single iteration (Seismosoft 2020).

\section{Material Constitutive Models}

\subsection{Concrete}

The constitutive relationship proposed by Mander, Priestley, and Park (1988) is a uniaxial nonlinear constant confinement model (Figure 8(a)). The confinement effects provided by the lateral transverse reinforcement are incorporated whereby constant confining pressure is assumed throughout the entire stress-strain range.

A stress-strain model is developed for concrete subjected to uniaxial compressive loading and confined by transverse reinforcement. The model allows for cyclic loading and includes the effect of strain rate. The influence of various types of confinement is taken into account by defining an effective lateral confining stress, which is dependent on the configuration of the transverse and longitudinal reinforcement (Mander, Priestley, and Park 1988).

Figure 8 (b) represents the actual concrete stress-strain curve used in nonlinear finite element modelling. 


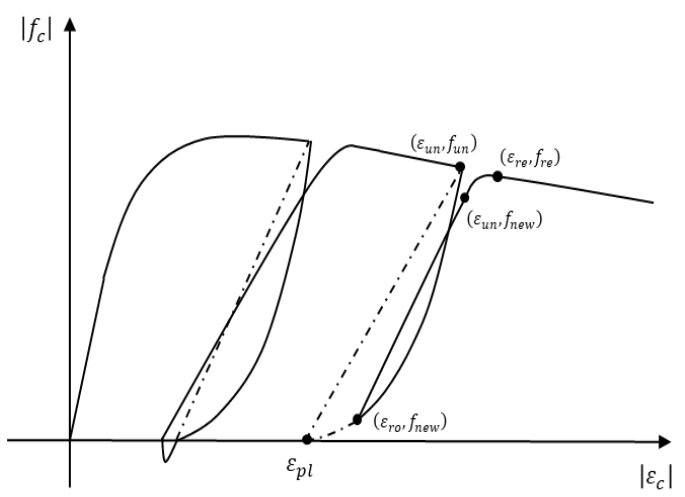

(a)

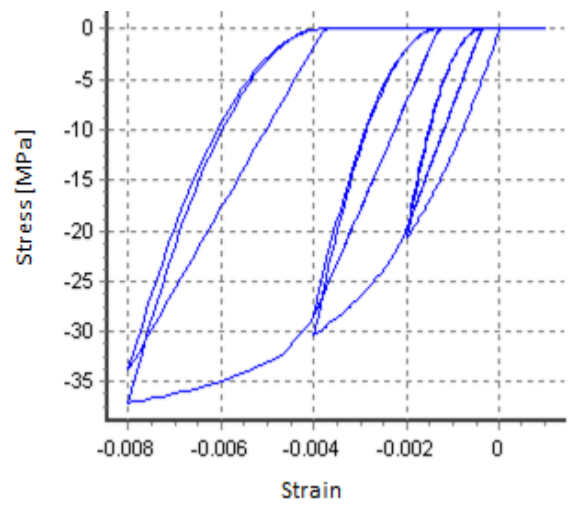

(b)

Figure 8: Concrete stress-strain curve: (a) Proposed by Mander, Priestley, and Park (1988); (b) Actual curve used for finite element modelling

\subsection{Reinforcement steel}

The constitutive relationship initially programmed by Menegotto and Pinto (1973) coupled with the isotropic hardening rules proposed by Taucer, Spacone, and Filippou (1991) represented in Figure 9(a), is a uniaxial steel model that can reproduce with good approximation the behavior of different types of steel. The constant $b$ defines the slope of the hardening line. The exponent $R$, which varies after every inversion, affects the curvature of the diagram, to represent the Bauschinger effect (Menegotto and Pinto 1973). Its employment is applied to the modelling of reinforced concrete structures, particularly those subjected to complex loading histories, where significant load reversals might occur.

Figure $9(b)$ is the actual steel stress-strain curve used for nonlinear finite element modelling.

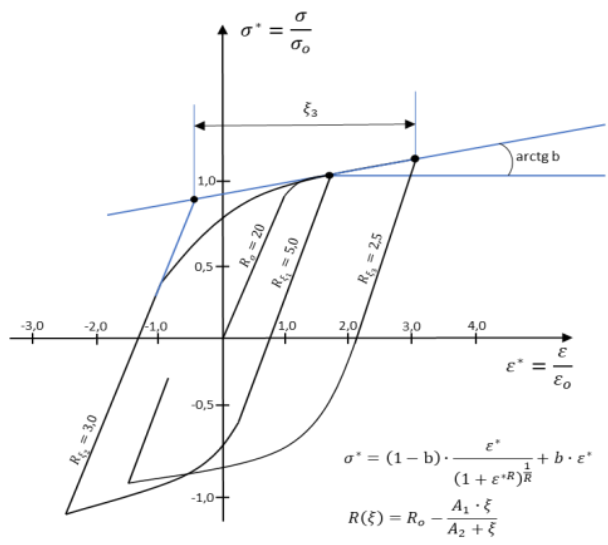

(a)

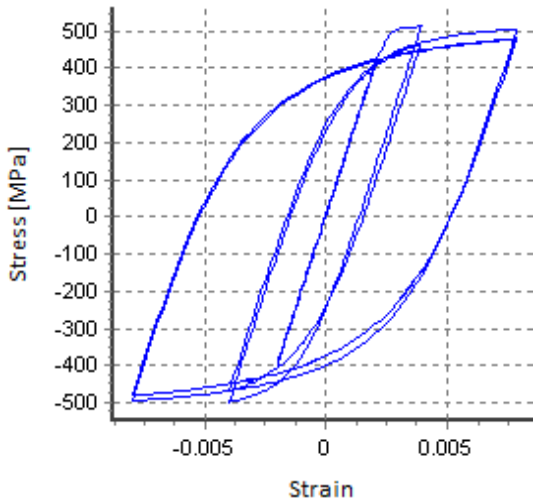

(b)

Figure 9: Steel stress-strain curve: (a) Proposed by Menegotto and Pinto (1973)

(b) Actual in finite modelling

\section{Failure Criterion for Modelling}

The models are based on material stress-strain relations and the corresponding material related failure criterion must be adopted to monitor de progressive failure of the column. When the strain at any integration point of a fiber, either concrete or steel, exceeds the material failure criterion, the fiber element stiffness is set to zero and no longer contributes to the stiffness computation.

\section{Results}

The following plots shows the comparison between the cyclic envelope curves, obtained from experimental data, and the pushover analysis, regarding the finite length hinge and the distributed fiber formulation models. 


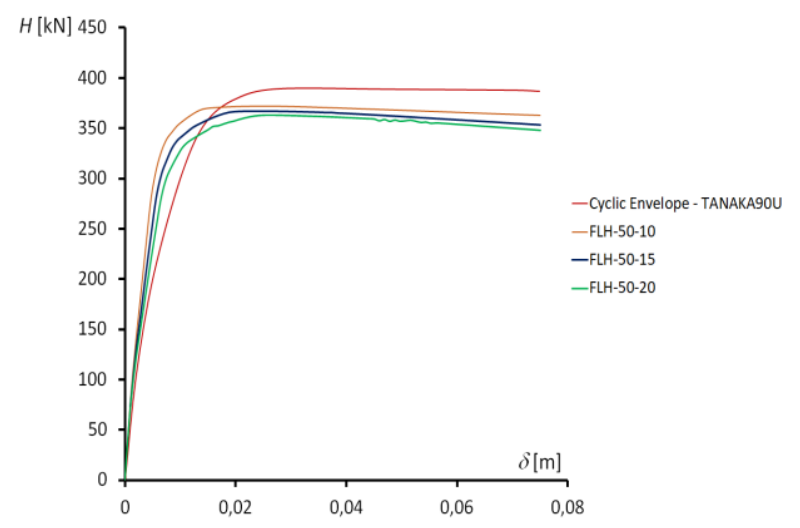

(a)

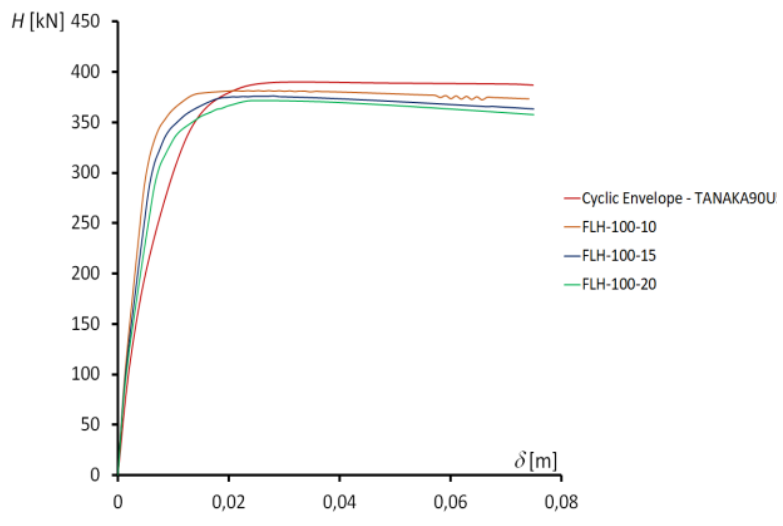

(b)

Figure 10: Comparison of experimental and numerical capacity curves-Finite length hinge model: (a) 50 fibers (b) 100 fibers

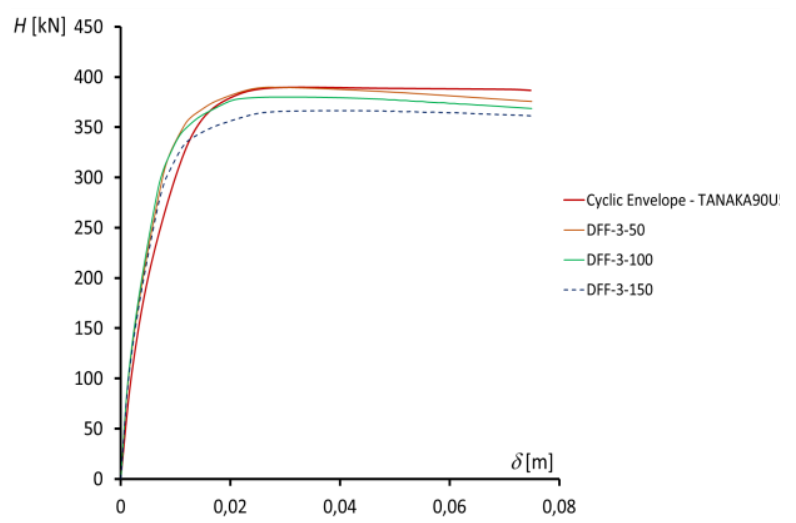

(a)

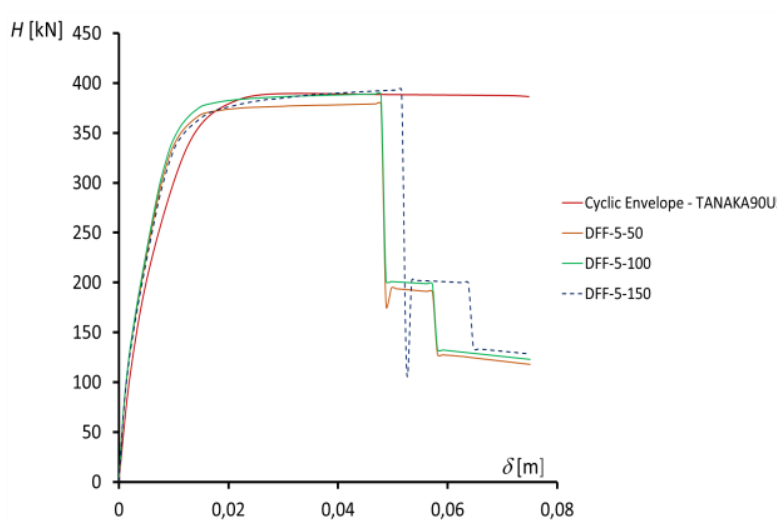

(b)

Figure 11: Comparison of experimental and numerical capacity curves-Distributed fiber formulation model: (a) 3 integration sections (b) 5 integration sections

Concerning the finite length hinge models, it can be observed that the overall models envelopes relatively well the experimental curves, although for FLH-50-10, FLH-50-15 and FLH50-15 models (Figure 10(a)), are slightly more distant from the peak base shear in regard to FLH-100-10, FLH-100-15 and FLH-100-15 models (Figure 10(b)).

Regarding the distributed fiber formulation models, the model with three integration section reveals closer to the experimental cyclic envelope curves (Figure 11(a)).

As it can be observed in Figure 11(b) there is a sudden resistance degradation for the models with five integration sections despite number of fibers. The model appears to be more sensitive when ultimate compressive strength is reached. The tensile stresses can still be transmitted due to crack bridging effects and a strain-softening behavior can be observed. Also, the distributed fiber formulation models DFF-5-50, DFF-5-100 and DFF-5-150, experiences hardening pushing forward the drift at peak base shear, changing the model stiffness drastically. The concrete compressive fiber strains in the hinge region quickly increase resulting in rapidly degrading material post-peak stiffness. As the number of integration sections increases from three to five, the length of the first integration section decreases and increasing curvatures are required to achieve the same prescribed tip displacement (FIB-FIPCEB 2008).

The model's performance of both modelling approaches is evaluated for maximum drift in the linear branch $\left(\delta_{\mathrm{e}}\right)$, drift at peak base shear $\left(\delta_{p}\right)$ and for peak base shear $\left(H_{\mathrm{p}}\right)$ response parameters. The percentage error with respect to the experimental data is computed as: 


$$
\operatorname{error}(\%)=\left|\frac{p_{\text {numerical }}-p_{\text {experimental }}}{p_{\text {experimental }}}\right| \times 100 \%
$$

where $p$ is a general term for each response parameter in question. The capacity curves shape enveloping the experimental cyclic curve has been also taken in consideration to assess the nonlinear finite element models analysis.

The response parameters error chart concerning finite length hinge models (Figure 12(a)), shows that there is an error of about $5 \%$ for the drift in the linear branch $\left(\delta_{\mathrm{e}}\right)$, despite the number of fibers and plastic hinge length $L_{\mathrm{p}}$. Considering the drift at the peak base shear $\left(\delta_{\mathrm{p}}\right)$, it is observed an error of 7\% for the FLH-50-10, FLH-50-15 and FLH-50-20 models and about 4\% for the FLH-100-10, FLH-100-15 and FLH-100-20 models, despite the plastic hinge length. The peak base shear $\left(H_{p}\right)$ results, show an error of $6 \%$ for FLH-50-10, FLH-50-15 and FLH-5020 models and $4 \%$ for FLH-100-10, FLH-100-15 and FLH-100-20 models, despite the plastic hinge length. Although it should be noted that the error is about $2 \%$ for the FLH-10-100 model.

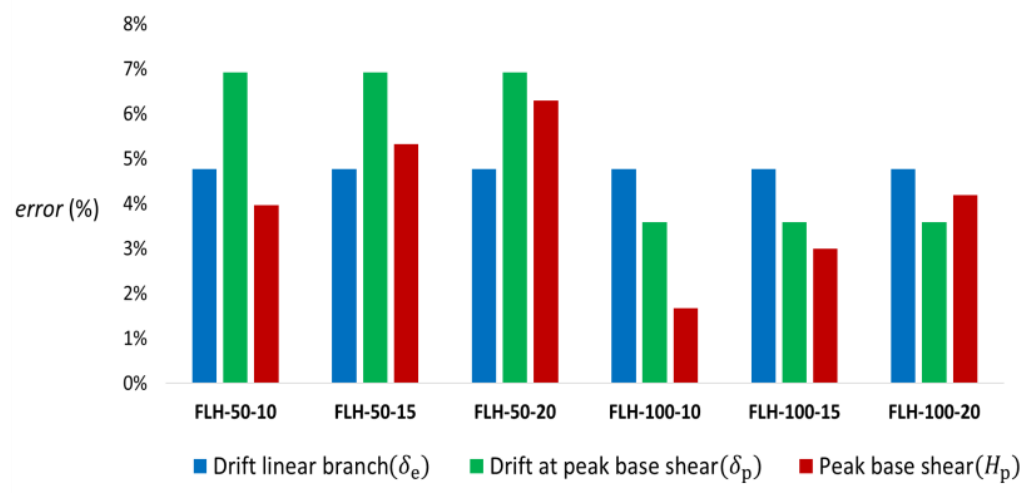

(a)

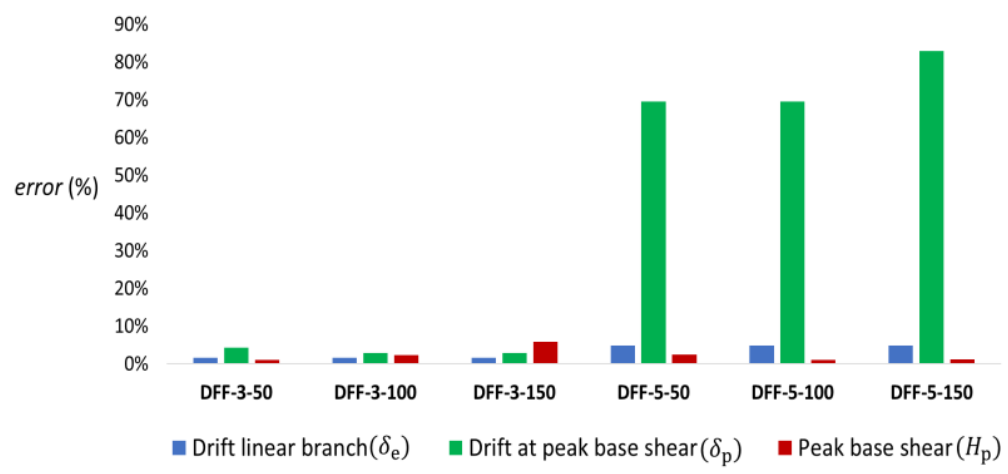

(b)

Figure 12: Error chart for response parameters: (a) Finite length hinge model

(b) Distributed fiber formulation

Figure 12(b) shows an error of about $2 \%$ for maximum drift in the linear branch for the overall models. Concerning the column drift at the peak base shear, it is observed an error of $4 \%$ for the DFF-3-50 and DFF-5-50 models and about 3\% for the DFF-3-150 and DFF-5-150 models. The peak base shear results show an error of $2 \%$ for the 50 fibers model and about $5 \%$ for the 150 fiber models, no mattering how many integration sections are.

Figure 13(a) and Figure 13(b) represent the column yield surface and the horizontal lines are the averaged evolution of the paired axial force-bending moment (N-M) internal forces along the pushover, for each type of nonlinear finite element model. The column combined flexure $(\mathrm{N}-\mathrm{M})$ in the pushover analysis reaches its maximum at the edge of the column yield surface, 
which demonstrates that the models capture the $\mathrm{N}-\mathrm{M}$ interaction response directly. It shall be noted that there is no variation of the axial force along the pushover analysis, as expected.

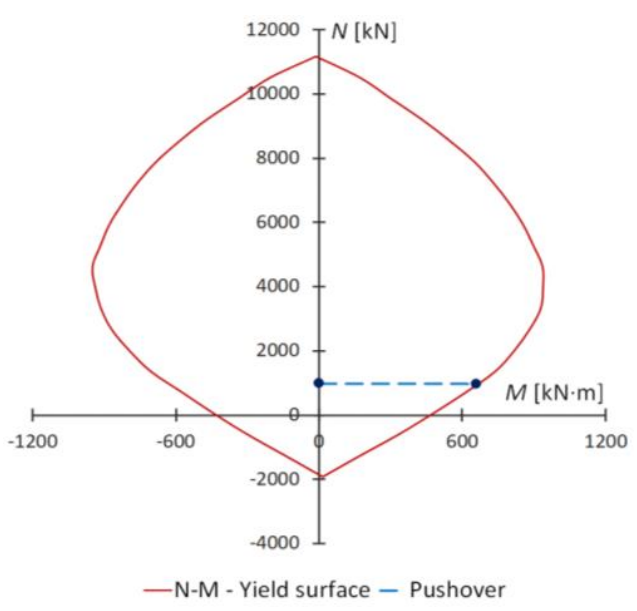

(a)

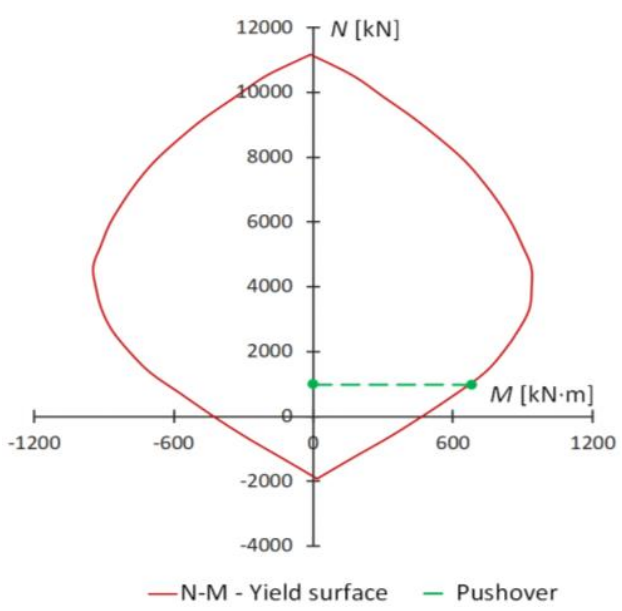

(b)

Figure 13: N-M interaction diagram (a) Finite length hinge models

(b) Distributed fiber formulation models

\section{Conclusions}

The models had mixed successes when attempting to simulate the response of the column in this study. Looking at the capacity curves, obtained by pushover analysis, both modeling approaches provide a good approximation to the experimental cyclic envelope curve, except for the distributed fiber formulation model with five integration sections.

The distributed fiber formulation models, with three integration sections, have been capable to predict the experimental response presenting an average error below 5\%, in regard with the parameters considered in the calibration. In the case of the model with five integration sections, it predicted peak base shear value quite well, but it failed to produce a realistic drift response at the same point. These models suggest that number of the integration sections influences the accuracy of the integration and the post-peak response. For hardening materials such as steel, plasticity spreads beyond a single integration section and numerical problems are related to a non-smooth response. For perfectly plastic and softening crosssection responses, the curvature tends to limit at a particular integration point causing problems with the model objectivity.

The finite length hinge models with 100 fibers presents an overall response parameter average error below $5 \%$ and should be underlined that the model with relative length hinge FLH-10010 presents the best fit against experimental data.

\section{References}

Deierlein, G. G., A. M. Reinhorn, and M. R. Willford. 2010. Nonlinear structural analysis for seismic design: A guide for practicing engineers. NIST GCR 10-917-5, NEHRP Seismic Design Technical Brief no. 4. National Institute of Standards and Technology. https://www.nehrp.gov/pdf/nistgcr10-917-5.pdf.

FIB-FIP-CEB. 2008. Practitioners' guide to finite element modelling of reinforced concrete structures. fib Bulletin no. 45. fib Fédération internationale du béton. https://doi.org/10.35789/fib.BULL.0045.

Mander, J. B., M. J. N. Priestley, and R. Park. 1988. "Theoretical stress-strain model for confined concrete". Journal of Structural Engineering-Asce 114, no. 8 (september): 180426. https://doi.org/10.1061/(Asce)0733-9445(1988)114:8(1804). 
Menegotto, M., and P. E. Pinto. 1973. "Method of analysis for cyclically loaded R. C. plane frames including changes in geometry and non-elastic behavior of elements under combined normal force and bending". IABSE Reports of the Working Commissions: 15-22. https://doi.org/10.5169/seals-13741.

Neuenhofer, A., and F. C. Filippou. 1997. "Evaluation of nonlinear frame finite-element models". Journal of Structural Engineering 123, no. 7 (july): 958-66. https://doi.org/10.1061/(ASCE)0733-9445(1997)123:7(958).

Seismosoft. 2020. "SeismoStruct 2020 - A computer program for static and dynamic nonlinear analysis of framed structures". https://seismosoft.com/.

Tanaka, H. 1990. "Effect of lateral confining reinforcement on the ductile behaviour of reinforced concrete columns". PhD diss., University of Canterbury. https://doi.org/10.26021/3137.

Taucer, F. F., E. Spacone, and F. C. Filippou. 1991. A fiber beam-column element for seismic response analysis of reinforced concrete structures. Report no. UCB/EERC-91/17. Earthquake Engineering Research Center, College of Engineering, University of California, Berkeley.

\section{Acknowledgments}

This work was financially supported by: Base Funding - UIDB/04708/2020 and Programmatic Funding - UIDP/04708/2020 of the CONSTRUCT - Instituto de I\&D em Estruturas e Construções - funded by national funds through the FCT/MCTES (PIDDAC). 